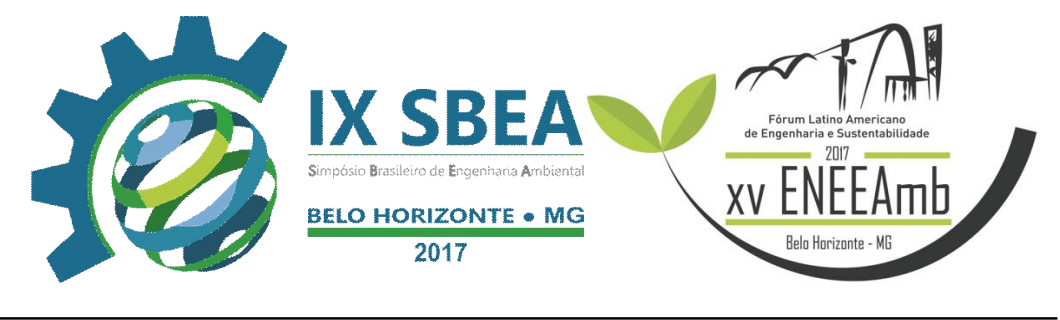

RESÍDUOS SÓLIDOS

\title{
AVIALIAÇÃO DO DESCARTE IMPRÓPRIO DE RESÍDUOS SÓLIDOS: ESTUDO DE CASO LAGOINHA SETOR HABITACIONAL SOL NASCENTE- DF
}

\author{
José Evandro Soaresï evandrosoares.df@gmail.com \\ Uninter- Centro Universitário Internacional
}

Bruna Sousa da Silvaï brunassilva@gmail.com

Associação dos Profissionais de Engenharia Ambiental do Distrito Federal Ï ASPEA-

DF

Guilherme da Silva Pereira ï sciguilherme@gmail.com

Associação dos Profissionais de Engenharia Ambiental do Distrito Federal Ï ASPEA-

DF

Ana Maria de Souza Rangelï anarangel@hotmail.com

GrupoGeo 




\section{RESUMO}

O Distrito Federal vem sofrendo com o crescimento desordenado, desde que o modelo de condomínios horizontais foi utilizado como modelos de expansão urbana, em sua grande maioria de forma irregular, sem qualquer planejamento urbano ou ambiental, assim gerando problemas futuros, como o depósito de resíduos sólidos em áreas irregulares, tendo em vista que não possui infraestruturas adequadas. $\mathrm{O}$ presente estudo tem por objetivo avaliar o descarte impróprio de resíduos sólidos na Lagoinha e em suas proximidades, área localizada na Unidade de Conservação Parque da Lagoinha, na Região Administrativa de Ceilândia, no Distrito Federal. Foram realizadas quatro visitas ao local de estudo, para analisar quais resíduos são lançados no local de forma irregular, para que seja possível levantar as categorias de resíduos existentes, a vulnerabilidade do local a possíveis contaminações e os potenciais impactos ambientais. A partir dos resultados, observou-se a necessidade de estudo de manejo para área a fim de propor sua revitalização, buscando impedir a contaminação do solo e da lagoa através de disposição inadequada de resíduos sólidos.

Palavras-chave: Crescimento desordenado, resíduos sólidos, contaminação, impacto ambiental, Sol Nascente.

\section{INTRODUÇÃO/OBJETIVO}

Dentre todas as espécies animais existentes, o ser humano é a que tem maior capacidade de adaptação e modificação do meio circundante, criando assim seu meio ambiente próprio, buscando através da modificação do meio, um ambiente mais adaptável a sua vivência. (DIAS, 2011)

O crescimento populacional e o intenso processo de urbanização, aliado ao consumo exagerado dos recursos naturais, são a perfeita combinação para 0 desequilíbrio ambiental, fenômeno que caracteriza o período atual, que vem se agravando. Nesta sociedade da comunicação, da tecnologia, muito mais das máquinas, do que de pessoas, tudo é fabricado para durar o menor tempo possível, para logo necessitar de novos produtos, e o planeta se torna um imenso depósito de resíduos (FRANÇA, 2009).

Embora considerados sinônimos, os termos lixo e resíduos sólidos, tem conceitos distintos. Segundo o dicionário Aurélio (FERREIRA, 2001, p. 1042) Lixo é $\tilde{n}[. .$.$] aquilo que se varre da casa, do jardim, da rua, e se joga fora; entulho; coisas$ 


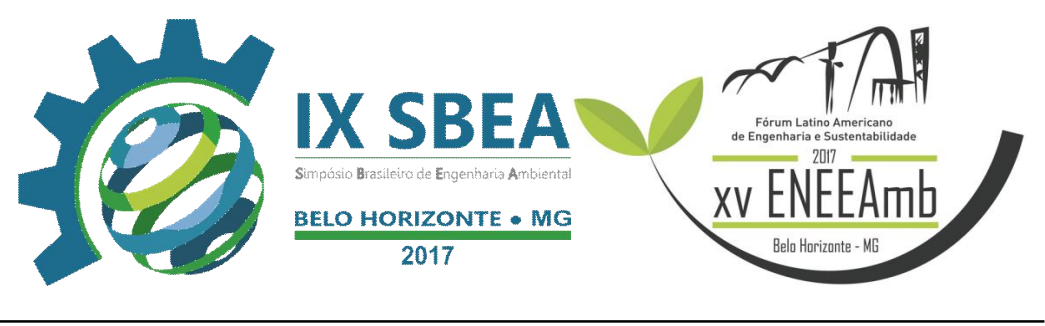

imprestáveisò. Já os resíduos sólidos, possuem valor agregado, que podem ser separados, reciclados ou reaproveitados com um potencial econômico respeitável (TAVARES, 2008).

Os lançamentos de resíduos em lixões a céu aberto acarretam geração de gases que causam odores desagradáveis e também contribuem para o efeito estufa, além de poluir o solo e as águas superficiais e subterrâneas pelo chorume produzido na decomposição da matéria orgânica (LANZA et al., 2010).

Outro ponto importante a se destacar quanto ao tema é o risco de acidentes com materiais perfurocortantes e ao contato direto com resíduos infectantes pode causar doenças para a saúde humana (GÜNTER, 2008).

É evidente que o homem precisa mudar sua forma de se relacionar com a natureza. As ações humanas devem estar voltadas principalmente à preservação de seu próprio ambiente, evitando que as gerações futuras sofram com a perda da capacidade do planeta em suportar os impactos antrópicos (GRIPPI, 2006).

Esse trabalho foi desenvolvido na área conhecida popularmente como ñLagoinhaò, que sofre com a disposição irregular de resíduos sólidos. O trabalho tem como objetivo avaliar o descarte impróprio de resíduos sólido e seus possíveis impactos, nesta área irregular, no Setor Habitacional Sol Nascente. A área em questão é inserida dentro da Unidade de Conservação Parque da Lagoinha, onde toda a unidade não possui mais vegetação nativa e encontra-se em estágio avançado de consolidação, a área de estudo pertence às poligonais do Setor Habitacional Sol Nascente, que está totalmente inserida na Região Administrativa de Ceilândia (RA IX), parte em Zona Urbana de Dinamização (ZUD) e parte em Zona Rural de Uso diversificado (ZRUD). Dentro da Zona Rural delimita-se a área Especial de Proteção Físico-ambiental denominadas Bordas de Ceilândia, conforme ilustrado na figura 1. 

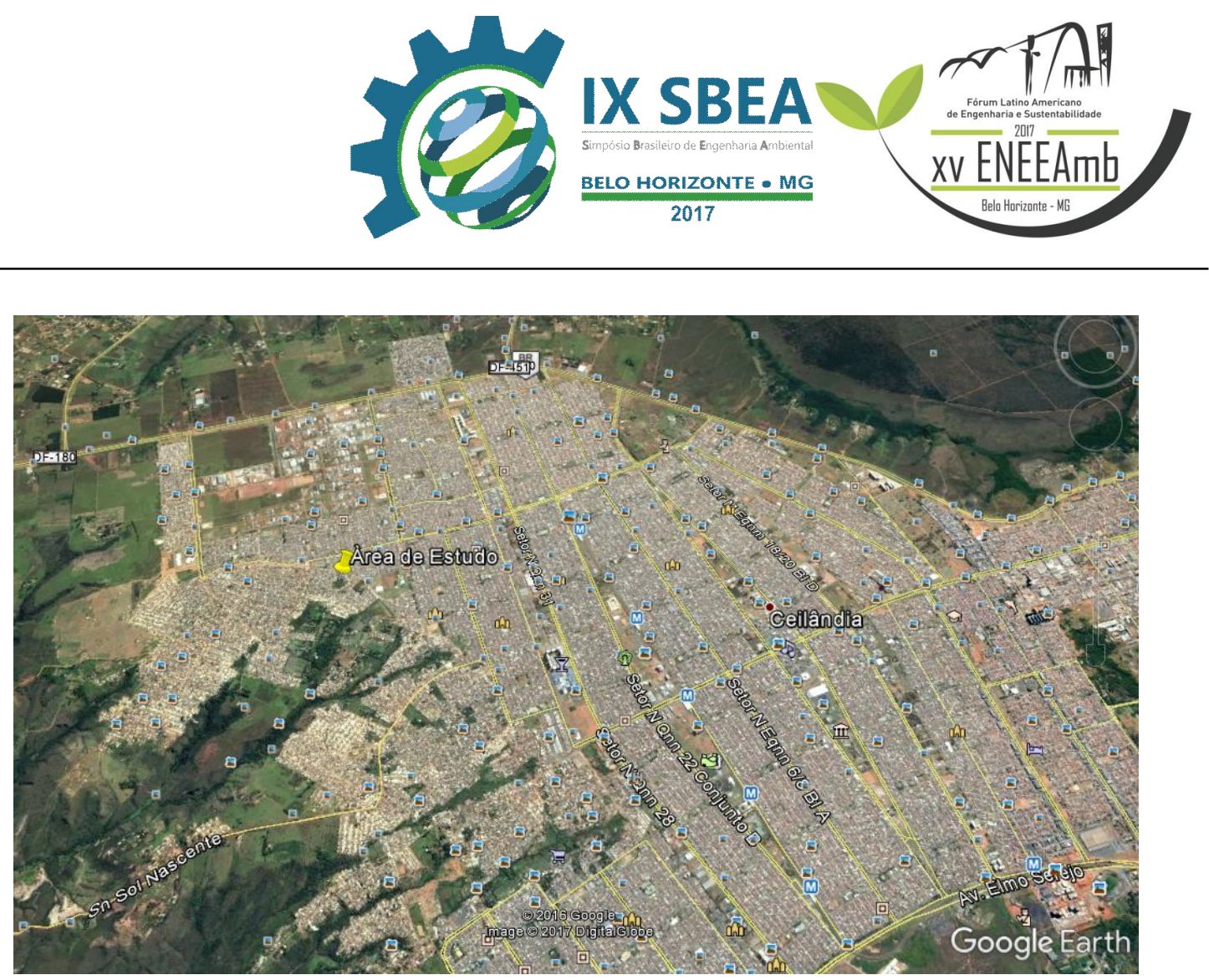

Figura 1: Mapa localização área de estudo

Fonte: Google Earth (junho 2017).

A pressuposição do presente trabalho é de que devam ser encontrados no local resíduos que se enquadram em todas as classes da norma NBR10004/2004, contaminando tanto a água como o solo, ocasionando sérios impactos ambientais negativos, uma vez que algumas substâncias presentes nos resíduos sólidos podem tornar o ecossistema insustentável e até mesmo provocar a morte de espécies animais e vegetais, dependendo da sua concentração.

Os resíduos e sua má condução trazem inúmeras consequências para o meio ambiente. Logo, pensar em alternativas como diagnosticar o local, onde são dispostos resíduos irregularmente e assim, avaliando quais são os resíduos dispostos no local de estudo e quais são os tipos de impactos que esses resíduos podem causar ao meio ambiente, sem dúvida, ajuda a minimizar o problema.

\section{METODOLOGIA}

Com base nos objetivos propostos, foi realizado através de pesquisa exploratório-descritiva, com o objetivo de ampliar o conhecimento a respeito dos resíduos sólidos, avaliação dos possíveis impactos causados ao local através dos resíduos dispostos inadequadamente na área de estudo. Quanto à tipologia da metodologia, optou-se por realizar inicialmente uma pesquisa bibliográfica, visando 


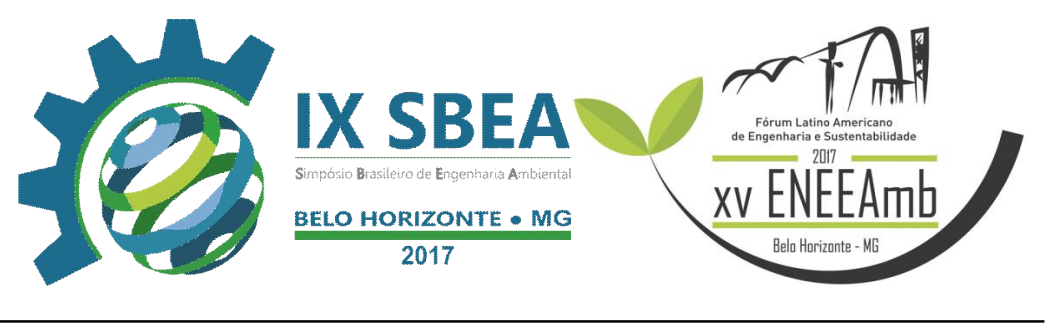

obter informações e conhecimento, juntamente com atividades realizadas em campo, na área de estudo, para análise das características do local e também identificar os aspectos dos resíduos e averiguar quais resíduos são dispostos no local.

\section{RESULTADOS E DISCUSSÃO}

A área de estudo é considerada uma área de grande sensibilidade ambiental e social. A regularização da ocupação urbana consolidada no Setor Habitacional Sol Nascente, exige cuidados especiais e o estabelecimento de diretrizes específicas para o local, pois o meio natural já se encontra bastante antropizado, com devastação das matas de galeria em alguns pontos, depósitos de lixo e entulho ao longo das vias de terra, deterioração da qualidade dos recursos hídricos, desestabilização dos solos, dentre outras ações predatórias.

À área de estudo corresponde um corpo hídrico pequeno, conhecido popularmente como Lagoinha, localizada no trecho III do Setor Habitacional Sol Nascente, na Região Administrativa de Ceilândia, com coordenadas geográficas 15²8'38.03"S/ 48 8'34.92"O, inserido na Unidade de Conservação Parque da Lagoinha, onde nota-se que toda a extensão do parque se encontra em estado antropizado consolidado.

A área em estudo apresenta como principal característica a presença de resíduos sólidos dispostos de maneira irregular. Quanto à origem dos resíduos dispostos no local pressupõe-se que tenham sido gerados em ambientes domiciliares e de construção civil já que se trata de uma área irregular, com frequentes operações de desocupação das novas unidades habitacionais que são construídas.

Quanto ao aspecto dos resíduos, muitos deles encontram-se há certo tempo no local, como resíduos de construção civil, isopor, plástico, fralda descartável, lata de alumínio, embalagem de energético, osso de animal, embalagem de água sanitária, lâmpadas, latas de tinta, entre outros, alguns resíduos dentro do corpo hídrico e outros muito próximos ao mesmo, como se pode observar na Figura 2. 

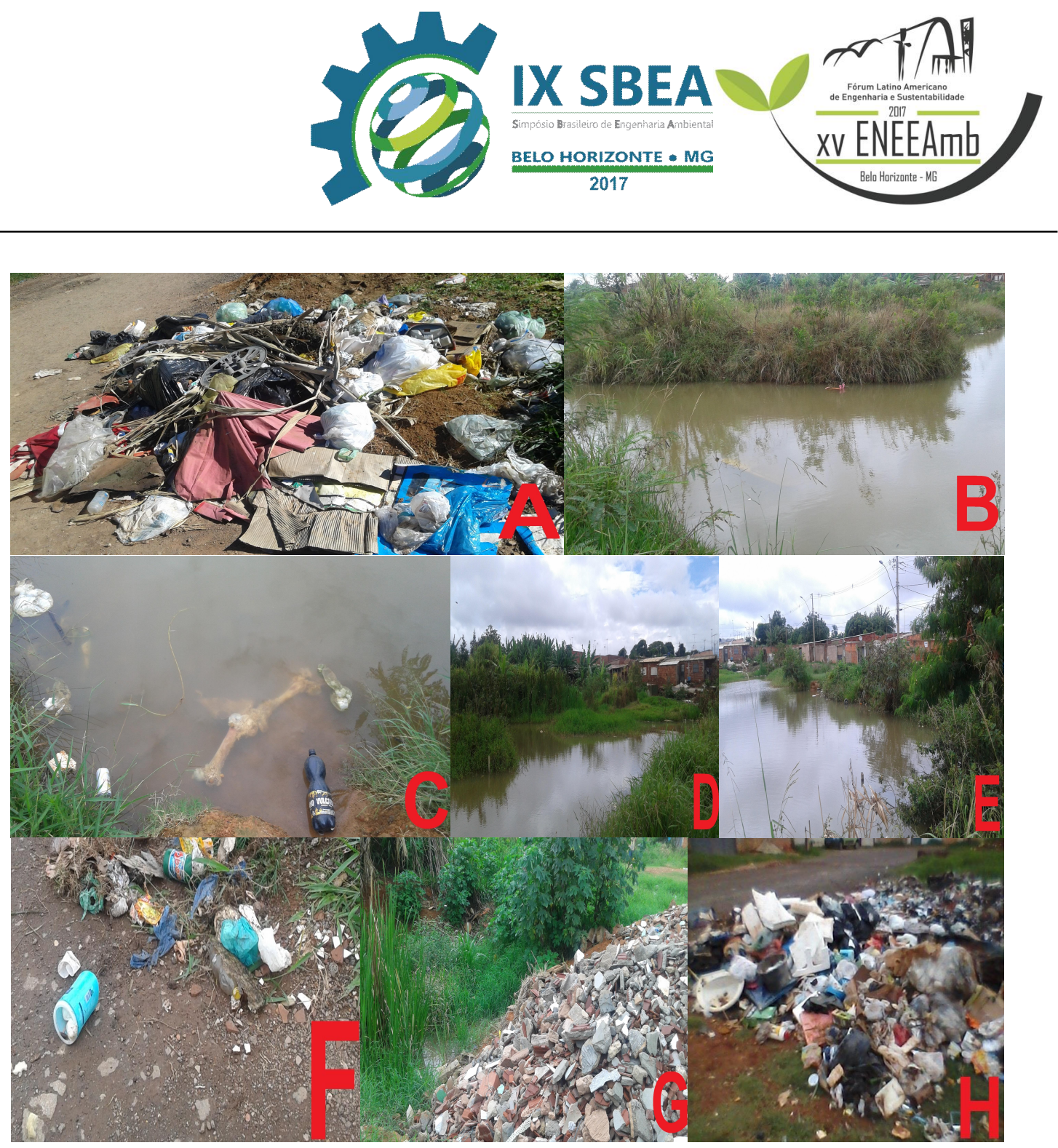

Figura 2. Resíduos sólidos identificados na área de estudo. (A) resíduos domésticos; (B) madeira e plástico e resto de equipamento eletrônico dentro da lagoa; (C) resto de animal, lata de cerveja, isopor, e embalagem de energético; (D) plástico; (E) pneu de carro e resto de lâmpada dentro da lagoa; (F) embalagem de água sanitária; (G) resto de construção civil; (H) e embalagem de tinta e querosene.

$\mathrm{Na}$ área de estudo também há presença de diversos equipamentos eletrônicos dispostos no local dentro da lagoa, como tubos de TVs, o que pode causar a liberação de substâncias nociva à saúde humana na água. Os resíduos sólidos urbanos (RSU) encontram-se em grande quantidade no local, sendo que alguns não considerados perigosos, causam mau cheiro, devido à decomposição da matéria orgânica. Também pode-se encontrar animais mortos em estado de apodrecimento o que acaba por trazer ao local organismos vetores que podem causar a proliferação de doenças para a população vizinha. 


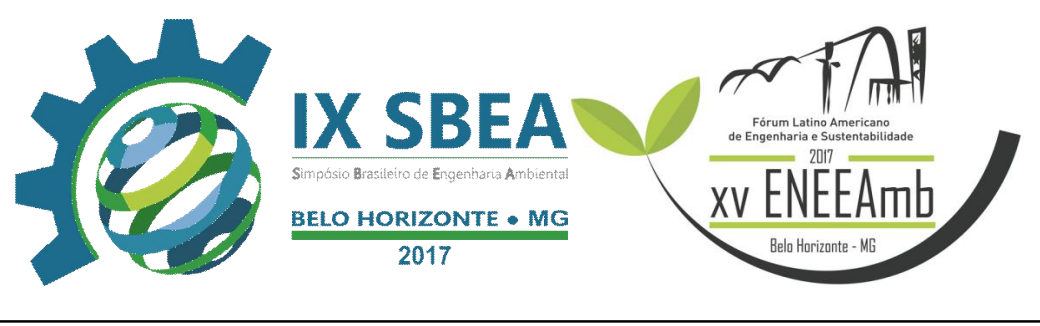

O solo e a água podem ser contaminados pelo chorume produzido por esses resíduos. Foi verificada também a presença de lâmpadas fluorescentes no local, e muitas vezes essas lâmpadas estão juntas com resíduos domiciliares, algumas vezes quebradas. As lâmpadas fluorescentes contêm o elemento mercúrio $(\mathrm{Hg})$, considerado um contaminante tóxico, capaz de provocar danos à saúde e ao meio ambiente.

Esses resíduos podem conter quantidades significativas de substâncias químicas nocivas ao meio ambiente e aos seres vivos, que podem acumular nos tecidos vivos, atingindo níveis perigosos para a saúde. Alguns exemplos são o mercúrio, encontrados em produtos farmacêuticos e lâmpadas fluorescentes, o cadmio em pilhas e baterias e o chumbo em inseticidas e tintas (BARREIRA, 2005).

Através das visitas realizadas no local foi possível elaborar uma tabela composta pelos resíduos domiciliares e de construção civil, os quais estão em grande número depositados inadequadamente no local.

Tabela 1. Principais resíduos sólidos encontrados na área de estudo.

\begin{tabular}{|c|c|}
\hline CONJUNTO & $\begin{array}{l}\text { RESÍDUOS ENCONTRADOS NA ÁREA DE } \\
\text { ESTUDO }\end{array}$ \\
\hline Plástico & $\begin{array}{l}\text { Sacos, sacolas, embalagens de refrigerante, água, } \\
\text { energéticos e leite, embalagens de produto de } \\
\text { limpeza, potes, embalagens de remédios. }\end{array}$ \\
\hline Orgânico & Restos alimentares, de animais e podas de árvores. \\
\hline Papel e papelão & Caixas, revistas, jornais, sacos de papel e livros. \\
\hline Panos, borracha & Roupas, pedaços de tecidos, sapatos, pneus. \\
\hline Resíduos não contaminantes & $\begin{array}{c}\text { Vasos de flores, restos de construção, resíduos } \\
\text { varrição. }\end{array}$ \\
\hline Madeiras & Móveis, restos de podas e tábuas. \\
\hline Vidro & $\begin{array}{l}\text { Garrafa de Bebida, embalagens de remédios, } \\
\text { lâmpadas, embalagens de produtos alimentícios. }\end{array}$ \\
\hline Metal ferroso & $\begin{array}{c}\text { Palhas de aço, embalagens de produtos } \\
\text { alimentícios. }\end{array}$ \\
\hline Metal não ferroso & Latas de bebida, resto de cobre, fiação elétrica. \\
\hline Contaminante químico & $\begin{array}{l}\text { Embalagens de produtos químicos, latas de óleo de } \\
\text { motor, latas com tintas. }\end{array}$ \\
\hline Contaminante biológico & $\begin{array}{c}\text { Fraldas descartáveis, algodão, cotonete e papel } \\
\text { higiênico. }\end{array}$ \\
\hline
\end{tabular}




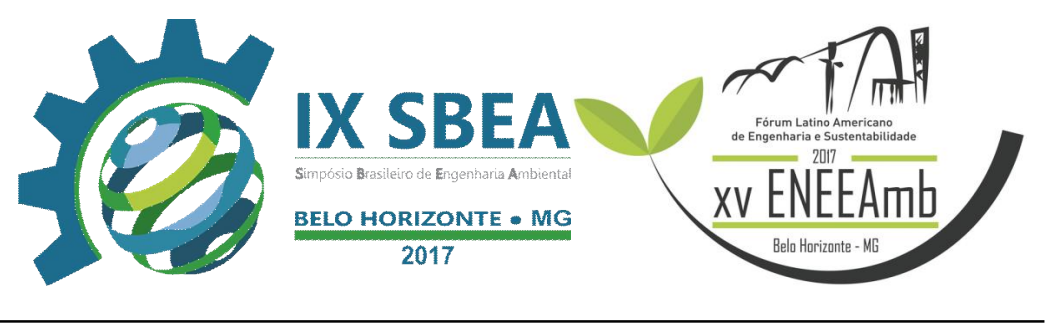

A tabela 2 apresenta os resíduos dispostos no local de estudo conforme a classe estabelecida pela NBR 10004:2004, que classifica os resíduos como Classe I-resíduos perigosos, Classe II- resíduos não perigosos, Classe IIA- Não Inertes e Classe IIBInertes.

Tabela 2. Classificação de resíduos sólidos, encontrados na área de estudo.

\begin{tabular}{|l|l|}
\hline Tipos de Resíduos & Classificação \\
\hline Lâmpadas fluorescentes e mistas & Classe I \\
\hline Restos de alimentos & Classe II A \\
\hline Resíduo orgânico (varrição) & Classe II A \\
\hline Sucata de metais ferrosos & Classe II B \\
\hline Resíduos de papel e papelão & Classe II A \\
\hline Resíduos plásticos (filmes pequenos embalagens) & Classe II B \\
\hline Resíduos de madeira (madeira não tratada) & Classe II A \\
\hline Resíduo de vidros & Classe II B \\
\hline Resíduos de tintas e pigmentos & Classe I \\
\hline Embalagens metálicas (latas vazias não contaminadas) & Classe II B \\
\hline Pneus & Classe II \\
\hline
\end{tabular}

Foram realizadas quatro visitas entre janeiro e maio de 2017 , a cada visita foi notado que o aspecto do local estava diferente, pela presença de novos resíduos dispostos no local. O que se pode avaliar é que a disposição de resíduos sólidos inadequadamente é constante, sem qualquer tipo de controle ou fiscalização. Por se tratar de uma área em processo de regularização fundiária e ambiental é nítida que a lugares apropriados para disposição dos resíduos, falta de conscientização e política ambiental que contemplem as etapas de disposição ambientalmente adequada dos resíduos, são fatores que repercutem em perigos a saúde ambiental e humana.

\section{CONCLUSÕES/RECOMENDAÇÕES}

O crescimento populacional desordenado em grande parte do Distrito Federal, induziu ao aumento da taxa de consumo e, consequentemente, extensa produção de resíduos. Tal tema tornou-se uma preocupação mundial, no entanto, houve exemplo internacional que apresentasse efetiva solução. Enquanto o acúmulo inadequado de 


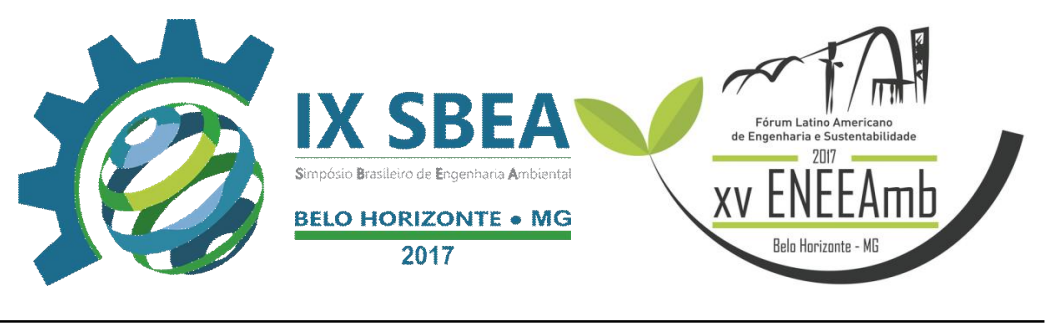

resíduos continua apresentando ameaça ao meio ambiente, tendo-se em vista a quantidade exagerada que vem sendo produzida, esta realidade tem preocupado setores significativos da sociedade, o que tem levado governos e especialistas a buscarem soluções que minimizem o impacto provocado pelo lixo.

Observa-se que os tipos de resíduos gerados e dispostos inadequados no local de estudo independem da origem, sendo que há uma parcela de impacto ambiental no local. São resíduos que estão presentes no meio urbano, e que sem nenhum tipo de gerenciamento são dispostos inapropriadamente no local. Sendo de grande facilidade de descarte pelos seus geradores, os resíduos são eliminados sem receber o mínimo de cuidado necessário em relação ao tipo de impacto que podem causar. Isso também acontece pela falta de conscientização da população. A forma de como são descartados faz refletir como a falta de serviço de coleta implica em sérios danos ambientais e que por se tratar de uma área irregular não existe uma coleta adequada.

Outro ponto que chama a atenção é quanto à classificação dos resíduos sólidos encontrados no local de estudo. Percebe-se que área em estudo pode estar sofrendo uma degradação causada pela toxicidade dos resíduos e por se tratar de uma área que está inserida na Unidade de Conservação Parque da Lagoinha a fiscalização e o cuidado deveriam ser bem maiores.

É de extrema necessidade um gerenciamento para os resíduos, cabendo ao poder público tomar a iniciativa de proporcionar à população a forma ambientalmente correta de como gerenciar e acondicionar os resíduos em suas próprias residências. Uma recomendação é o melhor aproveitamento dos resíduos orgânicos, por exemplo, separando os resíduos de forma adequada de maneira a poder reciclar ou reaproveitar ao máximo com o compromisso de evitar o descarte inadequado, evitando a contaminação ambiental.

O gestor público deve ter como foco a gestão dos resíduos sólidos, também em áreas irregulares, levando em consideração diversos aspectos como a educação ambiental e a conscientização da população ao descartar seus resíduos.

\section{REFERÊNCIAS BIBLIOGRÁFICAS}




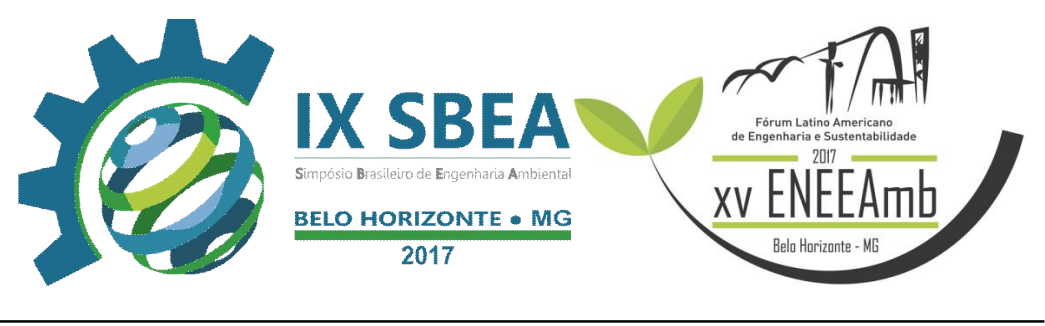

DIAS, Reinaldo. Gestão Ambiental: responsabilidade social e sustentabilidade. São Paulo: Atlas, 2011. 2 ed. 232 pag.

FERREIRA, Aurélio Buarque de Holanda. Novo Dicionário Aurélio da Língua

Portuguesa, 2 ed. Versão ampliada, Rio de Janeiro: Nova Fronteira, 2001.

FRANÇA, R. G.; RUARO, E. C. R. Diagnóstico da disposição final dos resíduos sólidos urbanos na região da associação dos municípios do Alto Irani (AMAI), Santa Catarina. In: Ciência \& Saúde Coletiva 14(6): 2191-2197; Universidade Comunitária da Região de Chapecó; Santa Catarina, 2008.

GOUVEIA, Nelson. Resíduos sólidos urbanos: impactos socioambientais e perspectiva de manejo sustentável com inclusão social. Disponível em: Acesso em: 10 maio. 2017.

GRIPPI, Sidney. Lixo: reciclagem e sua história: guia para prefeituras brasileiras / Sidney Grippi. -2. ed.- Rio de Janeiro: Interciência,2006. p 4, 21

GÜNTHER, W. M.R. Resíduos sólidos no contexto da saúde ambiental. São Paulo, 2008. Disponível em: www.teses.usp.br/teses/disponiveis/.../6/tde.../Textolivredocwandarisso.pdf. Acesso e: 09/12/2013. p 126

LANZA, V.C. V; MACHADO, R. M. G; TORQUETTI, Z.S. C; FERNANDES, P. R. M; REIS,A. G; TEIXEIRA, C. Z. Fundação Estadual do Meio Ambiente. Reabilitação de áreas degradadas por resíduo sólidos urbanos /Fundação Estadual do Meio Ambiente; Fundação Israel Pinheiro.ï Belo Horizonte:FEAM, 2010.Disponível em: www.feam.br/images/stories/Flavia/areas_degradadas.pd. Acesso em: 07/05/2017.

TARVARES, Jimy Carter Lima. Caracterização dos Resíduos Sólidos Urbanos da cidade de Maceió - Al. 2008. 114p. Dissertação (Mestrado em Engenharia: Recursos Hídricos e Saneamento) - Universidade Federal de Alagoas. Centro de Tecnologia, Maceió. 